\title{
MODEL ARSITEKTUR LAYANAN ADMINISTRASI PEMERINTAHAN SISTEM PEMERINTAHAN BERBASIS ELEKTRONIK (SPBE) PEMERINTAH DAERAH KUNINGAN
}

\author{
Alifiani S Qotrunnisa ${ }^{1}$, Soni F S Gumilang ${ }^{2}$, Ryan A Nugraha ${ }^{3}$ \\ 1,2,3 Program Studi Sistem Informasi, Fakultas Rekayasa Industri, Universitas Telkom \\ Email: ${ }^{1}$ alifianisyh@gmail.com, ${ }^{2}$ mustonie@ @elkomuniversity.ac.id ${ }^{3}$ ranugraha@ telkomuniversity.ac.id
}

(Naskah masuk: 18 Agustus 2021, diterima untuk diterbitkan: 4 September 2021)

\begin{abstract}
Abstrak
Teknologi dan informasi yang berkembang menimbulkan dampak yang positif salah satunya dalam pelaksanaan operasional sebuah organisasi dengan menyelaraskan strategi bisnis dan strategi teknologi informasi. Seperti halnya yang terjadi pada Pemerintah Indonesia, dengan memanfaatkan perkembangan teknologi dan informasi maka mulai melakukan penerapan Sistem Pemerintahan Berbasis Elektronik dalam rangka meningkatkan pelayanan publik dan memberikan kemudahan dalam penyampaian informasi. SPBE diatur dalam Peraturan Presiden No. 95 Tahun 2018 guna mempermudah dalam melakukan penerapan SPBE khususnya pada tingkat pemerintahan daerah. Dalam mendukung visi, misi, dan program yang telah ditetapkan sebelumnya. Berdasarkan hasil evaluasi SPBE oleh KemenPAN-RB, Pemkab. Kuningan berada pada kategori cukup dan belum memiliki standardisasi layanan SPBE. Hal ini yang menjadikan belum optimalnya penerapan SPBE dari segi layanan SPBE. Penelitian ini bertujuan untuk melakukan optimalisasi terhadap layanan SPBE yang berorientasi terhadap proses bisnis dan aplikasi yang sudah ada maupun yang belum ada yang menjadi target dalam penelitian ini. Sehingga mampu meningkatkan mutu pelayanan pemerintahan dengan meningkatkan kecepatan dan ketepatan pengelolaan data dan informasi publik pada Pemkab. Kuningan. Solusi pada penelitian ini berupa perancangan Enterprise Architecture SPBE pada domain layanan menggunakan kerangka kerja kombinasi antara TOGAF ADM dengan arsitektur SPBE sehingga dapat menghasilkan beberapa output melalui tiga tahap preliminary phase, architecture vision, dan arsitektur layanan. Arsitektur layanan berperan dalam mengidentifikasi layanan dari aplikasi pusat dan daerah sehingga hasil penelitian ini digambarkan dalam bentuk katalog layanan administrasi pemerintahan dan matrik bidang/proses bisnis berdasarkan proses bisnis level 0 program prioritas pada Pemkab. Kuningan yang mampu meningkatkan mutu pelayanan khususnya internal birokrasi Pemkab.Kuningan.
\end{abstract}

Kata kunci: Arsitektur Layanan, Enterprise Architecture, SPBE, TOGAF ADM

\section{MODEL OF GOVERNMENT ADMINISTRATION SERVICES ARCHITECTURE BASED ELECTRONIC GOVERNMENT SYSTEM (SPBE) KUNINGAN LOCAL GOVERNMENT}

\begin{abstract}
Developing technology and information has a positive impact, one of which is on the operational implementation of an organization by aligning business strategies and information technology strategies. As is the case with the Government of Indonesia, by utilizing the development of technology and information, it has begun to implement an Electronic-Based Government System in order to improve public services and provide convenience in the delivery of information. SPBE is regulated by Presidential Regulation No. 95 of 2018 to make it easier to implement SPBE, especially at the local government level. In support of the vision, mission, and programs that have been set previously. Based on the results of the SPBE evaluation by the KemenPAN-RB, Kuningan Regency is in the sufficient category and does not yet have standardized SPBE services. This is what makes the implementation of SPBE in Kuningan Regency not optimal in terms of SPBE services. This study aims to optimize $S P B E$ services that are oriented towards existing and non-existing business processes and applications that are the targets of this research. So as to improve the quality of government services by increasing the speed and accuracy of the management of public data and information at the Regency Government. Brass. The solution in this research is in the form of SPBE Enterprise Architecture design in the service domain using a combination framework between TOGAF ADM and SPBE architecture so that it can produce several outputs through three stages of preliminary phase, architecture vision, and service architecture. The results of this study are described in the form of a catalog of government administration services and a matrix of business fields/processes based on
\end{abstract}


business processes level 0 priority programs at the Kuningan Regency Government, which is able to improve the quality of service, especially in the internal bureaucracy of the Kuningan Regency Government.

Keywords: Service Architecture, Enterprise Architecture, SPBE, TOGAF ADM

\section{PENDAHULUAN}

Teknologi dan informasi yang berkembang dengan pecat memberikan kemudahaan dalam mengakses dan menerima sebuah informasi [1]. Peran teknologi dan informasi mempengaruhi berbagai sektor dalam mewujudkan sistem yang efektif, efisien, transparan dan akuntabel sehingga dapat meningkatkan hasil kerja yang lebih cepat dan akurat [2]. Salah satu sektor yang terlibat dalam penerapan teknologi informasi berada pada sektor pemerintahan dalam memberikan pelayanan publik yang berkualitas [3]. Dalam mengupayakan hal tersebut, pemerintah Indonesia terdorong untuk membangun sistem pemerintahan berbasis elektronik atau $e$ government yang tebaik dan menyeluruh [4]. Penerapan e-government untuk mewujudkan pelayanan publik yang baik dengan melakukan integrasi alur proses bisnis sehingga mampu menghasilkan informasi yang layak diterima oleh masyarakat luas [5]. Berdasarkan data yang dipublikasikan oleh E-Government Development Index (EGDI) tahun 2020 Indonesia berada pada peringkat 88 dari 193 negara [6]. Dari indeks EGDI tersebut pemerintah Indonesia khususnya KemenpanRB menjadikan referensi sebagai bahan evaluasi tingkat kematangan dalam penerapan SPBE [7]. Berdasarakan peringkat EGDI pada tahun 2020, Denmark merupakan negara dengan peringkat nomor satu dengan indeks 0.98 kemudian pada peringkat dua yaitu Korea Selatan dengan indeks 0.97 .

Dengan demikian Pemerintah Indonesia melalui ketetapan Perpres Nomor 95 Tahun 2018 mengenai Sistem Pemerintahan Berbasis Elektronik (SPBE). Aturan yang telah dibuat memberikan penjelasan bahwa SPBE dimanfaatkan untuk memberikan tata kelola pemerintahan yang efektif, efisien, transparan, dan akuntabel sehingga mampu meningkatkan pelayanan publik [8]. SPBE digunakan sebagai sarana dalam mengimpementasikan teknologi informasi dan komunikasi dalam memberikan layanan [9]. Adanya peraturan presiden mengenai SPBE maka pemerintah pusat dan daerah harus bersinergi dalam mewujudkan tatanan pemerintahan yang lebih baik. Hal ini yang menjadikan Pemerintah Daerah Kabupaten Kuningan perlu melakukan standardisasi SPBE untuk mewujudkan mutu pelayanan, akuntabilitas dan transparansi pemerintahan dengan meningkatkan kecepatan dan ketepatan pengelolaan data dan informasi publik.

Berdasarkan kondisi Pemerintah Daerah Kabupaten Kuningan diatas, dibutuhkan perancangan enterprise architecture untuk mempermudah dalam penggambaran arsitektur SPBE. Arsitektur SPBE merupakan kerangka kerja yang digunakan dalam melakukan proses integrasi antara proses bisnis hingga keamanan SPBE yang meliputi infrastruktur dan aplikasi untuk menghasilkan layanan yang memiliki integrasi [8]. Sedangkan EA merupakan perancangan artefak yang digunakan untuk menyelarasakan antara bisnis dengan teknologi informasi dengan menyusun keseluruhan proses bisnis, teknologi pendukung, dan informasi [10]. Dalam menyusun arsitektur SPBE diperlukan enam domain yang terlibat diantaranya proses bisnis, data dan informasi, infrastruktur, aplikasi, keamanan, dan layanan. Layanan SPBE menghasilkan layanan administrasi pemerintahan dan layanan publik berbasis elektronik [11]. Penelitian ini bertujuan untuk menjelaskan perancangan EA dari domain layanan SPBE dengan keluaran katalog layanan administrasi pemerintahan dan matrik bidang/proses bisnis Pemkab. Kuningan.

Dalam penelitian ini untuk mendapatkan keluaran berupa katalog layanan administrasi pemerintahan berbasis elektronik matrik bidang/proses bisnis diperlukan sebuah kerangka kerja yaitu TOGAF ADM dan arsitektur SPBE. TOGAF ADM merupakan kerangka kerja dalam merancang EA yang dapat disesuaikan dengan kebutuhan suatu organisasi dan dapat digabungkan dengan kerangka kerja lainnya sehingga dapat menghasilkan artefak yang spesifik [12]. TOGAF ADM memiliki 9 fase yaitu Preliminary Phase, Architecture Vision, Business Architecture, Information System Architecture, Technology Architecture, Opportunities and Solutions, Migration Planning, Implementation Governance, Architecture Change Management [13]. Sedangkan arsitektur SPBE bertujuan untuk memetakan secara jelas mengenai integrasi antara proses bisnis hingga menghasilkan layanan SPBE [14]. Dengan demikian perancangan ini menggabungkan antara dua kerangka kerja yaitu TOGAF ADM dan arsitektur SPBE dalam menggambarkan kondisi SPBE Pemkab. Kuningan yang berfokus pada layanan administrasi pemerintah berbasis elektronik sehingga dapat meningkatkan pelayanan kepada masyarakat Kabupaten Kuningan.

\section{METODE PENELITIAN}

Tahapan dalam melakukan penelitian dengan memberikan penjelasan terhadap alur perancangan EA SPBE pada lingkungan Pemerintahan Kabupaten Kuningan pada domain layanan terbagi menjadi tiga yaitu tahap inisasi, analisis dan perancangan, dan kesimpulan dan saran dapat dijelaskan pada Gambar 1. Metode Penelitian. 

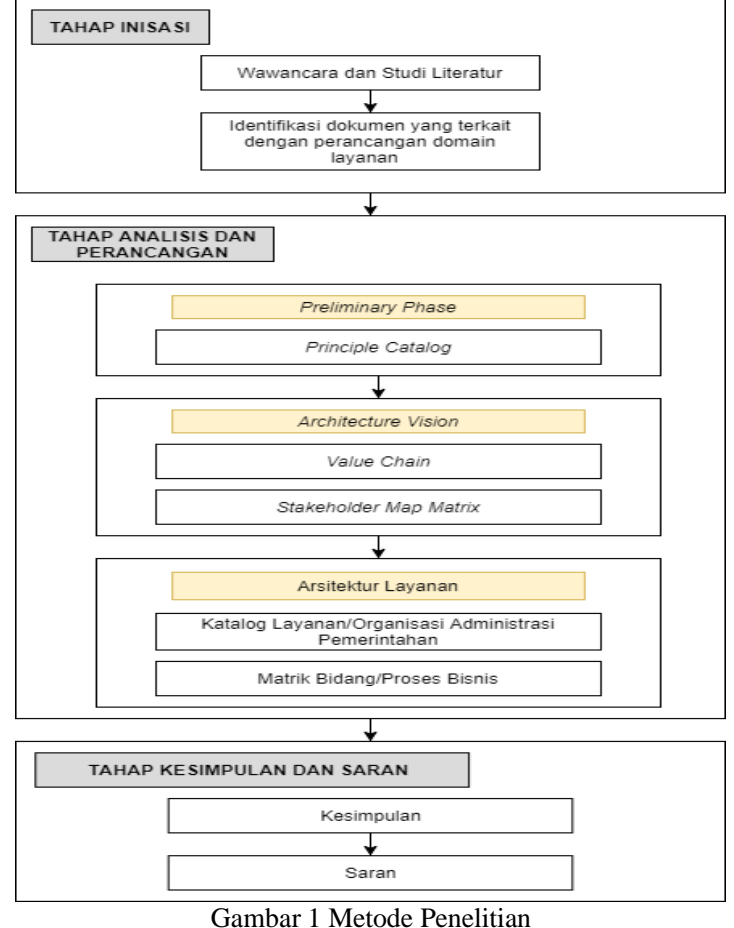

Tahap awal dalam penelitian ini yaitu tahap inisiasi yang berfokus untuk memulai penelitian. Langkah awal dalam tahap inisiasi dimulai dari pengenalan secara mendasar mengenai SPBE. Hal ini bisa dilakukan dengan melakukan wawancara dan studi literatur terhadap objek penelitian yaitu Pemkab. Kuningan. Tujuannya untuk mengetahui kondisi SPBE pada saat untuk menidentifikasi permasalahan yang sedang dihadapi oleh Pemkab. Kuningan. Metode wawancara merupakan cara atau teknik yang dapat dilakukan untuk memperoleh data yang dibutuhkan dengan memberikan beberapa pertanyaan kepada pihak atau narasumber dari Pemkab. Kuningan. Langkah selanjutnya yaitu melakukan studi literatur dengan memperlajari beberapa dokumen yang terkait dengan SPBE sebagai pedoman dalam perancangan EA SPBE pada domain layanan yaitu Perpres Nomor 95 tahun 2018 dan RPJMD tahun 2018-2023.

Tahap kedua yaitu analisis dan perancangan dengan melakukan identifikasi dan perancangan katalog sesuai dengan kebutuhan Pemkab. Kuningan pada domain layanan. Langkah pertama yaitu mengidentifikasi melalui preliminary phase yang menghasilkan artefak principle catalog menjelaskan mengenai prinsip-prinsip layanan untuk pengembangan SPBE pada Pemkab. Kuningan. Selanjutnya architecture vision menghasilkan value chain yang berisi nilai-nilai yang dihasilkan dari beberapa kegiatan pada Pemkab. Kuningan. Adapun stakeholder map matrix menjelaskan beberapa stakeholder yang memiliki kepentingan dalam pembangunan SPBE Pemkab. Kuningan baik secara internal dan eksternal. Langkah selanjutnya yaitu penggambaran arsitektur layanan dengan output katalog layanan/organisasi. Katalog ini memetakan layanan administrasi pemerintahan berbasis elektronik Pemkab. Kuningan berdasarkan fungsi terkait yang telah dijelaskan pada Peraturan Presiden Nomor 95 Tahun 2018. Selanjutnya melakukan identifikasi terhadap bidang yang sebelumnya sudah dijelaskan dengan proses bisnis level 0 pada program prioritas sesuai dengan RPJMD tahun 2018-2023 Kabupaten Kuningan untuk mendapatkan layanan yang memiliki keterhubungan antara bidang dengan proses bisnis.

Tahapan yang terakhir yaitu kesimpulan dan saran. Setelah melakukan identifikasi data dan analisis perancangan sehingga mendapatkan kesimpulan serta saran mengenai hasil dari perancangan EA SPBE domain layanan pada Pemkab. Kuningan. Kesimpulan serta saran dapat digunakan sebagai acuan dalam melakukan implementasi SPBE ke arah yang lebih baik dengan memanfaatkan kemajuan teknologi dan informasi.

\section{HASIL DAN PEMBAHASAN}

\subsection{Preliminary Phase}

Preliminary phase adalah fase awal dalam perancangan EA sesuai dengan kebutuhan Pemkab. Kuningan. Tujuan dari fase ini adalah menetapkan architecture capability dengan mendefinisikan prinsip-prinsip arsitektur khususnya layanan pada Pemkab. Kuningan tersebut [15]. Prinsip arsitektur digunakan sebagai acuan dalam setiap perancangan arsitektur selanjutnya seperti Tabel 2. Principle Catalog.

\begin{tabular}{ll} 
& Tabel 1. Principle Catalog \\
\hline Arsitektur & Prinsip \\
\hline & Sederhana \\
& Partisipatif \\
Layanan & Akuntabel \\
& Berkelanjutan \\
& Transparansi \\
& Keadilan \\
\hline
\end{tabular}

\subsection{Architecture Vision}

Pada fase architecture vision bertujuan untuk menjelaskan dan menggambarkan visi dari Pemkab. Kuningan sehingga mampu menghasilkan nilai-nilai penting dan stakeholder yang terlibat didalamnya [16]. Fase ini menghasilkan dua artefak yaitu value chain dan stakeholder map matrix.

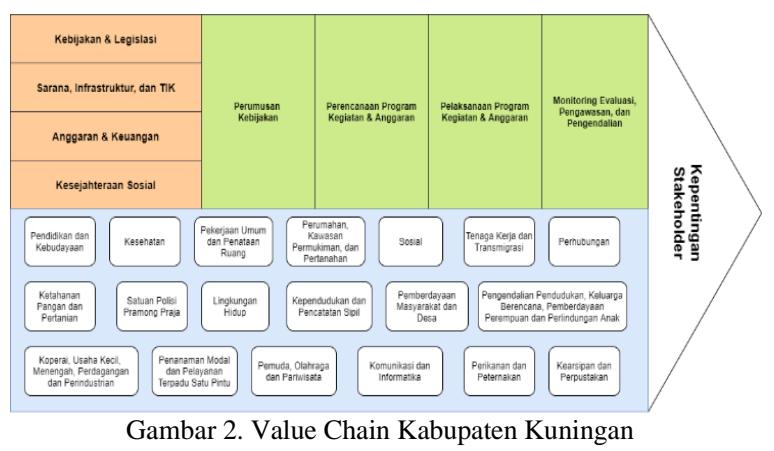


Tabel 3. Stakeholder Map Matrix

\begin{tabular}{|c|c|c|c|}
\hline No & Actor & Role & Class \\
\hline 1 & Bupati & $\begin{array}{l}\text { Bertanggung } \\
\text { jawab } \\
\text { terhadap } \\
\text { pelaksanaan } \\
\text { SPBE } \\
\text { Pemkab. } \\
\text { Kuningan }\end{array}$ & $\begin{array}{l}\text { Key } \\
\text { Player }\end{array}$ \\
\hline 2 & $\begin{array}{l}\text { Sekretari } \\
\text { at Daerah }\end{array}$ & $\begin{array}{l}\text { Mengoordinas } \\
\text { ikan } \\
\text { penerapan } \\
\text { kebijakan } \\
\text { SPBE } \\
\text { Pemkab. } \\
\text { Kuningan }\end{array}$ & $\begin{array}{l}\text { Keep } \\
\text { Informed }\end{array}$ \\
\hline 3 & $\begin{array}{l}\text { Dinas } \\
\text { Komunik } \\
\text { asi dan } \\
\text { Informati } \\
\text { ka }\end{array}$ & $\begin{array}{l}\text { Melakukan } \\
\text { pengelolaan } \\
\text { arsitektur } \\
\text { SPBE, } \\
\text { pengawasan } \\
\text { pembangunan } \\
\text { aplikasi, dan } \\
\text { infrastruktur } \\
\text { TIK Pemkab. } \\
\text { Kuningan }\end{array}$ & $\begin{array}{l}\text { Keеp } \\
\text { Informed }\end{array}$ \\
\hline 4 & $\begin{array}{l}\text { Bagian } \\
\text { Organiasi } \\
\text { Sekretari } \\
\text { at Daerah }\end{array}$ & $\begin{array}{l}\text { Mengoordinas } \\
\text { ikan integrasi } \\
\text { proses bisnis } \\
\text { Pemkab. } \\
\text { Kuningan }\end{array}$ & $\begin{array}{l}\text { Keep } \\
\text { Informed }\end{array}$ \\
\hline 5 & $\begin{array}{l}\text { BAPPED } \\
\text { A }\end{array}$ & $\begin{array}{l}\text { Mengoordinas } \\
\text { ikan } \\
\text { perencanaan } \\
\text { SPBE, tata }\end{array}$ & $\begin{array}{l}\text { Keеp } \\
\text { Informed }\end{array}$ \\
\hline
\end{tabular}

\begin{tabular}{lll} 
& & kelola data, \\
& dan & \\
& manajemen & \\
& data Pemkab. & \\
& Kuningan & \\
$6 \quad$ BPKAD & Mengoordinas $\quad$ Keep \\
& ikan & Informed \\
& penganggaran & \\
& dan keuangan & \\
& SPBE & \\
& Pemkab. \\
& Kuningan \\
\hline
\end{tabular}

\subsection{Arsitektur Layanan}

Arsitektur layanan merupakan tahapan utama dalam penelitian ini dengan memberikan satu keluaran berupa katalog layanan administrasi pemerintahan dan matrik bidang/proses bisnis pada Pemkab. Kuningan. Katalog ini didapatkan dari hasil analisis dan identifikasi aplikasi yang dikembangkan oleh pemerintah pusat maupun daerah sehingga menghasilkan suatu layanan yang bermanfaat bagi internal birokrasi Pemkab. Kuningan. Layanan administrasi pemerintahan dipetakan berdasarkan bidang pada Perpres Nomor 95 Tahun 2018 diantaranya bidang perencanaan, penganggaran, keuangan, pengadaan barang dan jasa, kepegawaian, kearsipan, pengelolaan barang milik negara, pengawasan, dan, akuntabilitas kinerja. Pada katalog layanan administrasi pemerintahan Pemkab. Kuningan terdapat penjelasan mengenai penyedia dan pengguna layanan yang selaras dengan bidang, aplikasi, dan layanan yang dihasilkan. Berikut merupakan penggambaran dari katalog layanan administrasi pemerintahan Kabupaten Kuningan.

Tabel 4. Katalog Layanan Administrasi Pemerintah Kabupaten Kuningan

\begin{tabular}{|c|c|c|c|c|}
\hline Bidang & Layanan & Aplikasi Pendukung & Penyedia Layanan & $\begin{array}{c}\text { Pengguna } \\
\text { Layanan }\end{array}$ \\
\hline Perencanaan & $\begin{array}{l}\text { Layanan } \\
\text { Perencanan }\end{array}$ & $\begin{array}{l}\text { SIPD (Sistem Informasi } \\
\text { Pemerintah Daerah) }\end{array}$ & $\begin{array}{ll}\text { - } & \text { Kementerian Dalam } \\
\text { Negeri } \\
\text { - } \\
\text { Kementerian Keuangan }\end{array}$ & BAPPEDA \\
\hline Penganggaran & $\begin{array}{l}\text { Layanan } \\
\text { Penganggaran }\end{array}$ & $\begin{array}{l}\text { SIPD (Sistem Informasi } \\
\text { Pemerintah Daerah) }\end{array}$ & $\begin{array}{l}\text { - Kementerian Dalam } \\
\text { Negeri } \\
\text { - Kementerian Keuangan }\end{array}$ & BPKAD \\
\hline Keuangan & $\begin{array}{l}\text { Layanan } \\
\text { Pengelolaan } \\
\text { Keuangan } \\
\text { Daerah }\end{array}$ & $\begin{array}{lr}\text { SIPKD } & (\text { Sistem } \\
\text { Informasi } & \text { Pengelolaan } \\
\text { Keuangan Daerah) }\end{array}$ & $\begin{array}{l}\text { - Direktorat Jendral } \\
\text { Keuangan Daerah } \\
\text { - Kemendagri }\end{array}$ & BPKAD \\
\hline $\begin{array}{l}\text { Pengelolaan } \\
\text { Barang Milik } \\
\text { Negara }(\mathrm{BMN})\end{array}$ & $\begin{array}{l}\text { Layanan } \\
\text { Pengelolaan } \\
\text { Barang Milik } \\
\text { Negara }\end{array}$ & $\begin{array}{l}\text { SIMAK BMN (Sistem } \\
\text { Informasi Manajemen } \\
\text { dan Akuntansi BMN) }\end{array}$ & - Kementerian Keuangan & BPKAD \\
\hline & $\begin{array}{l}\text { Layanan } \\
\text { Persediaan }\end{array}$ & Aplikasi Persediaan & - $\quad$ BPPKAD & BPKAD \\
\hline $\begin{array}{l}\text { Pengadaan } \\
\text { Barang \& Jasa }\end{array}$ & $\begin{array}{l}\text { Layanan } \\
\text { Pengadaan } \\
\text { Online }\end{array}$ & Aplikasi Pengadaan & - $\quad$ LKPP & $\begin{array}{l}\text { Setda Bagian } \\
\text { Pengadaan } \\
\text { Barang / Jasa }\end{array}$ \\
\hline Kepegawaian & Layanan & $\begin{array}{l}\text { SIRUP } \\
\text { Informasi } \quad \text { Ristem } \\
\text { Umum Pengadaan }) \\
\text { e-Kinerja }\end{array}$ & - BKPSDM & $\begin{array}{l}\text { Setda Bagian } \\
\text { Pengadaan } \\
\text { Barang / Jasa } \\
\text { BPKSDM }\end{array}$ \\
\hline
\end{tabular}




\begin{tabular}{|c|c|c|c|c|}
\hline & $\begin{array}{l}\text { Kinerja } \\
\text { Pegawai }\end{array}$ & & & \\
\hline & Layanan & SIMPEG & - BPKSDM & BPKSDM \\
\hline & Pengelolaan & Informasi Manajemen & & \\
\hline & Data Pegawai & Kepegawaian) & & \\
\hline & & SAPK (Sistem Aplikasi & - $\mathrm{BKN}$ & BPKSDM \\
\hline & Administrasi & Pelayanan & & \\
\hline & Kepegawaian & Kepegawaian) & & \\
\hline & Umum & & & \\
\hline Akuntabilitas & Layanan & e-SAKIP & - Setda & BPKSDM \\
\hline Kinerja & Pengelolaan & Akuntabilitas Kinerja & & \\
\hline & Akuntabilitas & Instansi Pemerintah) & & \\
\hline & Kinerja & Aplikasi & - Setda & BPKSDM \\
\hline & Instansi & (Penilaian & Organisasi & \\
\hline & & Aparatur) & $\begin{array}{l}\text { Pendayagunaan } \\
\text { Aparatur }\end{array}$ & \\
\hline Monitoring dan & Layanan & e-MONEV (Monitoring & - Setda & Setda Bagian \\
\hline Evaluasi & $\begin{array}{l}\text { Monitoring } \\
\text { dan Evaluasi }\end{array}$ & dan Evaluasi) & & $\begin{array}{l}\text { Administrasi } \\
\text { Pembangunan }\end{array}$ \\
\hline & & Aplikasi TEPRA (Tim & Bagian & Setda Bagian \\
\hline & & Evaluasi dan & Pembangunan & Pembangunan \\
\hline & & Pengawasan Realisasi & & \\
\hline Kearsipan & Layanan & SISUMAKER (Sistem & - Diskominfo & Dinas \\
\hline Naskah Dinas & Pengelolaan & Informasi Surat Masuk & - Kemenkumham & Kearsipan \\
\hline & Naskah Dinas & dan Surat Keluar) & & dan \\
\hline & dan Kearsipan & & ional & $\begin{array}{l}\text { Perpustakaan } \\
\text { Dinas }\end{array}$ \\
\hline & & Informasi Kearsipan & Republik Indonesia & Kearsipan \\
\hline & & Dinamis Terintegrasi) & & $\begin{array}{l}\text { dan } \\
\text { Perpustakaan }\end{array}$ \\
\hline
\end{tabular}

Keluaran selanjutnya yaitu matrik bidang/proses bisnis yang dikelompokkan berdasarkan bidang yang sudah dijelaskan sebelumnya dengan proses bisnis level 0 sesuai dengan program prioritas Pemkab. Kuningan. Proses bisnis level 0 secara khusus diidentifikasi oleh arsitektur bisnis diantaranya tata kelola pemerintahan yang akuntabel, peningkatan kecepatan dan ketepatan pengelolaan data dan informasi publik, peningkatan kinerja pengelolaan pendapatan asli dan keuangan daerah. Berikut merupakan tabel matrik bidang/proses bisnis.

Tabel 5. Matrik Bidang Proses Bisnis Layanan Administrasi Pemerintah

\begin{tabular}{|c|c|c|c|}
\hline $\begin{array}{l}\text { Bidang/ } \\
\text { Proses Bisnis }\end{array}$ & $\begin{array}{lr}\text { Tata } & \text { kelola } \\
\text { pemerintahan } & \text { yang } \\
\text { akuntabel } & \\
\end{array}$ & $\begin{array}{l}\text { Peningkatan kecepatan dan } \\
\text { ketepatan pengelolaan data dan } \\
\text { informasi publik }\end{array}$ & $\begin{array}{l}\text { Peningkatan } \\
\text { pengelolaan pendapatan asli } \\
\text { dan keuangan daerah }\end{array}$ \\
\hline Perencanaan & N/A & N/A & Layanan Perencanaan \\
\hline Penggangaran & N/A & N/A & Layanan Penggangaran \\
\hline Keuangan & N/A & N/A & $\begin{array}{l}\text { Layanan Pengelolaan } \\
\text { Keuangan Daerah }\end{array}$ \\
\hline $\begin{array}{l}\text { Pengelolaan } \\
\text { Barang Milik } \\
\text { Negara }\end{array}$ & N/A & $\begin{array}{l}\text { Layanan Pengelolaan Barang } \\
\text { Milik Negara }\end{array}$ & N/A \\
\hline Kepegawaian & N/A & $\begin{array}{l}\text { Layanan Pengelolaan Data } \\
\text { Pegawai dan Administrasi } \\
\text { Kepegawaian Umum }\end{array}$ & N/A \\
\hline $\begin{array}{l}\text { Pengawasan } \\
\text { Akuntabilitas } \\
\text { Kinerja }\end{array}$ & N/A & N/A & N/A \\
\hline $\begin{array}{l}\text { Monitoring } \\
\text { dan Evaluasi }\end{array}$ & $\begin{array}{l}\text { Layanan Monitoring } \\
\text { dan Evaluasi }\end{array}$ & N/A & N/A \\
\hline
\end{tabular}

\section{KESIMPULAN}

Berdasarkan penelitian perancangan enterprise architecture SPBE yang berfokus pada domain layanan Pemkab. Kuningan melalui tiga tahapan diantaranya 
preliminary phase, architecture vision, dan arsitektur layanan. Sehingga menghasilkan beberapa output diantaranya principle catalog menjelaskan mengenai prinsip-prinsip utama yang digunakan pada domain layanan untuk merancang EA. Kemudian pada fase architecture vision menghasilkan value chain yang menggambarkan bagian-bagian penting dalam Pemkab. Kuningan dalam menjalankan kegiatan dan stakeholder map matrix menjelaskan pemangku kepentingan pada Pemkab. Kuningan dalam menjalankan SPBE. Tahap arsitektur layanan menghasilkan katalog layanan administrasi pemerintahan yang dipetakan berdasarkan bidang pada Perpres Nomor 95 Tahun 2018, selanjutnya diselaraskan dengan aplikasi pusat dan daerah sejumlah 16 yang digunakan oleh Pemkab. Kuningan sehingga mampu menghasilkan 11 layanan. Kemudian pada keluaran matrik bidang/proses bisnis menghasilkan 6 layanan dari 7 bidang dari 3 proses bisnis level 0 sesuai dengan program prioritas sehingga dapat dimanfaatkan untuk meningkatkan kepentingan internal birokrasi Pemkab. Kuningan.

\section{DAFTAR PUSTAKA}

[1] P. H. Parsaorantua, Y. Pasoreh, dan S. A. Rondonuwu. 2017. "Implementasi Teknologi Informasi Dan Komunikasi (Studi Tentang Web E-Government Di Kominfo Kota Manado)"., $e$ journal "Acta Diurna", vol. VI, no. 3, pp. 1-2.

[2] A. A. Bouty, M. H. Koniyo, dan D. Novian. 2019. "Evaluasi Sistem Pemerintahan Berbasis Elektronik Menggunakan E-Government Maturity Model (Kasus di Pemerintah Kota Gorontalo)"., Jurnal Penelitian Komunikasi Dan Opini Publik, vol. 23, no. 1, pp. 16-17.

[3] R. H. Pratama. 2015. "Pelayanan Publik Berbasis Teknologi Informasi Dan Komunikasi (Tik), Elektronik Rukun Tetangga/Rukun Warga (E-Rt/Rw) (Studi E-Government Di Kelurahan Ketintang Kecamatan Gayungan Pemerintah Kota Surabaya)"., Jurnal Administrasi Publik, vol. 3, no. 12, pp. 21282132.

[4] W. F. M. Haryono, R. Mulyana, dan N. Ambarsari. 2019. "Perancangan Information System Architecture Menggunakan Togaf Adm Pada Fungsi Promosi (Studi Kasus: Dinas Pariwisata dan Kebudayaan Pemerintah Kabupaten Bandung Barat)"., Fountain of Informatics Journal, vol. 5, no. 1, p. 1.

[5] A. R Pamungkas, L. Edi Nugroho, dan S. Sulistyo. 2020. "Evaluasi Faktor Kegagalan Sistem Informasi Pada Kesiapan Penerapan EGovernment: Studi Literatur",, JIKO (Jurnal Informatika dan Komputer), vol. 3, no. 3, pp. 143-152.

[6] United Nations. 2020. "UN E-Government Knowledgebase". Tersedia [https://publicadministration.un.org/egovkb/enus/Data-Center] diakses 21 Oktober 2020.
[7] O. Lola. 2020. "Penilaian Penerimaan EGovernment Di Indonesia”., Jurnal CoreIT, vol. 6, no. 1, pp. 15-21.

[8] Peraturan Presiden Republik Indonesia Nomor 95 Tahun 2018 tentang Sistem Pemerintahan Berbasis Elektronik, Jakarta: Kementerian Sekretariat Negara Republik Indonesia.

[9] A. A. Afri, R. Fauzi, dan R. Mulyana. 2020. "Perancangan Manajemen Risiko Proyek Pada Spbe Berdasarkan Permen Panrb Nomor 5 Tahun 2020: Studi Kasus Di Pemerintah Kota Bandung”., e-Proceeding of Engineering, vol. 7, no. 2, pp. 7387-7392.

[10] A. H. Fikri, W. Purnomo, dan W. H. N. Putra. 2020. "Perancangan Enterprise Architecture Menggunakan TOGAF ADM pada PT. Hafintech Prima Mandiri”, Jurnal Pengembangan Teknologi Informasi dan Ilmu Komputer, vol. 4, no. 7, pp. 2032-2042.

[11] P. Dipa, P. Pratiwi, G. Agung, A. Putri, G. Made, dan A. Sasmita. 2020 "Evaluasi SPBE pada Dinas Kesehatan Salah Satu Kabupaten di Bali”., JITTER (Jurnal Ilmiah Teknologi dan Komputer), vol. 1, no. 2. p. 1.

[12] E. Nurmiati, Zulfiandri, dan A. Mughni. 2020. "Perencanaan Enterprise Architecture Menggunakan TOGAF Architecture"., Applied Information Systems and Management (AISM), vol. 3, no. 1, pp. 59-68.

[13] V. Soraya dan W. S. Sari. 2020 "Perancangan Enterprise Architecture Sistem Informasi dengan Menggunakan Framework TOGAF ADM pada CV. Garam Cemerlang”., JOINS (Journal of Information System), vol. 4, no. 2, pp. 148-156. Doi: 10.33633/joins.v4i2.3054.

[14] M. M. Fathoni, B. M. Izzati, dan Falahah. 2020. "Perancangan Enterprise Architecture Sistem Pemerintahan Berbasis Elektronik Pada Bidang Pertanahan Menggunakan TOGAF ADM ( Studi Kasus: Dinas Perumahan Permukiman Provinsi Jawa Barat ) Design of Enterprise Architecture Electronic Based Government System"., e-Proceeding of Engineering, vol. 7, no. 2, pp. 7271-7277.

[15] T. Maisari dan A. A. Nur Fajrillah. 2020. "Pengembangan SDM Dalam Arsitektur Bisnis Sebagai Strategi Dalam Optimasi Produktivitas Kinerja SDM"., Jurnal Sisfokom (Sistem Informasi dan Komputer), vol. 9, no. 1, p. 122. Doi: 10.32736/sisfokom.v9i1.804.

[16] Z. Rifai, T. Bratakusuma, dan R. Arvianti. 2020. "Perencanaan Arsitektur Enterprise Desa Dengan Kerangka Kerja TOGAF ADM"., Jurnal Sisfokom (Sistem Informasi dan Komputer), vol. 9, no. 2, p. 177. Doi: 10.32736/sisfokom.v9i2.803. 